\title{
Pulmonary Mycobacterium avium complex infection: association with NRAMP1 polymorphisms
}

\author{
G. Tanaka*, J. Shojima*, I. Matsushita*, H. Nagai", A. Kurashimađ, K. Nakata*, \\ E. Toyota ${ }^{+}$, N. Kobayashi ${ }^{+}$, K. Kudo ${ }^{+}$and N. Keicho*
}

ABSTRACT: The present study aimed to elucidate risk factors for nonimmunocompromised pulmonary Mycobacterium avium complex (MAC) infection.

Epidemiological data and variations of candidate genes for mycobacterial diseases were analysed in 111 patients with pulmonary MAC infection. Four polymorphisms of the human natural resistance-associated macrophage protein (NRAMP) 1 gene, the 5' (GT)n, 469+14 G/C, D543N and the 3'untranslated region (3'TGTG) insertion/deletion, were genotyped using PCR-based methods. Fok I and Taq I polymorphisms of the vitamin $D$ receptor gene and $-221 \mathrm{X} / \mathrm{Y}$ and codon 54 A/B polymorphisms of the mannose binding lectin gene were also evaluated.

Females were more susceptible to MAC infection mainly affecting the right middle lobe or lingular segment of the lung. Patients' residence at the onset of the disease was distributed evenly irrespective of a waterfront or city water supply system. As compared with homozygotes for major alleles of the D543N and TGTG insertion/deletion polymorphism of the NRAMP1 gene, heterozygotes containing minor alleles were less often observed in MAC cases than in controls. This genetic effect was more significant in patients without comorbidity but not in patients with comorbidity. Other polymorphisms did not show any association with the MAC infection.

The human natural resistance-associated macrophage protein 1 gene might be involved in susceptibility to pulmonary Mycobacterium avium complex infection.

KEYWORDS: Mannose binding lectin, Mycobacterium avium complex, natural resistanceassociated macrophage protein 1 , vitamin $D$ receptor

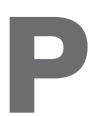

ulmonary Mycobacterium avium complex (MAC) infection causes chronic pulmonary diseases. MAC occurs in the natural environment and the common source of infection appears to be water, soil or dust, with human-tohuman transmission considered uncommon [13]. As an opportunistic pathogen, MAC causes disseminated disease in immmunocompromised hosts, such as individuals with HIV infection. However, there is evidence that the number of patients with MAC infection is increasing not only in AIDS-endemic areas but also in many other areas of the world, including Japan [4, 5].

Patients with underlying chronic lung diseases, such as inactive tuberculosis (TB), chronic obstructive pulmonary disease or cystic fibrosis, sometimes develop pulmonary MAC infection [5], which may be explained by significant damage to local immunity in the lung. Individuals without any obvious immunosuppressive state or any evidence of previous pulmonary disease, especially middle-aged to elderly females, also develop pulmonary MAC infections [6, 7]. In most patients, a radiographical pattern consisting of small centrilobular nodules corresponding to foci of granulomatous inflammation and bronchiectasis of the middle lobe, lingular segment and other lobes can be seen $[8,9]$. These lesions often expand, causing impairment of pulmonary function and, in severe cases where the treatment is difficult, a fatal outcome may occur [6]. A recent study implied that the sibling risk for MAC infection is much higher than its population prevalence estimated from an incidence rate of 3.52 per 100,000 in Japan [4, 10]. A complex interaction between genetic and environmental factors is thus considered.

The natural resistance-associated macrophage protein (Nramp)1 gene determines susceptibility to intracellular pathogens in mice [11]. A human homologue, NRAMP1, recently designated as solute carrier $11 \mathrm{a} 1$, was identified in the region

\section{AFFILIATIONS}

*Dept of Respiratory Diseases,

Research Institute and

${ }^{+}$Division of Respiratory Disease

International Medical Center of

Japan, and

Divisions of ${ }^{\#}$ Respiratory Disease and

- Clinical Research, National Hospital Organization Tokyo Hospital, Tokyo, Japan.

\section{CORRESPONDENCE}

N. Keicho

Dept of Respiratory Diseases

Research Institute

International Medical Center of Japan

1-21-1 Toyama

Shinjuku-ku

Tokyo 162-8655

Japan

Fax: 81332071038

E-mail: keicho@ri.imcj.go.jp.

Received:

March 252006

Accepted after revision:

April 182007

\section{SUPPORT STATEMENT}

This work was supported in part by research grants for Research on the Human Genome, Tissue Engineering and Food Biotechnology from the

Ministry of Health, Labour and

Welfare of Japan, by the Organization for Pharmaceutical Safety and

Research in 2002 and 2003 and by Grants-in-Aid for Scientific Research on Priority Areas from the Ministry of Education, Culture, Sports, Science and Technology of Japan in 2001-2005.

\section{STATEMENT OF INTEREST}

None declared.

European Respiratory Journal Print ISSN 0903-1936

Online ISSN 1399-3003 
of $2 q 35$, and variations of the NRAMP1 gene were studied for mycobacterial diseases including TB and leprosy [12-16]. In cases of MAC infection, the number of subjects is small [10, 17, 18], and, to date, no population-based studies have investigated the contribution of NRAMP1 to pulmonary MAC infection with a relatively large sample size. As other candidate genes, polymorphisms of the vitamin $\mathrm{D}$ receptor $(V D R)$ and mannose binding lectin $(M B L)$ genes are known to be associated with TB [19, 20], presumably playing an important role in intracellular growth of the pathogen. Thus, the clinico-epidemiological background of the disease was characterised and a case-control association study was conducted to determine whether polymorphisms of the three representative candidate genes are involved in the development of pulmonary MAC infection.

\section{MATERIAL AND METHODS}

\section{Study subjects}

In total, 111 Japanese cases of pulmonary MAC infection were included in the current study. Written informed consent was obtained from each individual. The present study protocol was approved by the local ethical committees. Out of the 111 subjects, 86 patients were from the International Medical Center of Japan and 25 were from the National Hospital Organization Tokyo Hospital (both Tokyo, Japan). A group of 177 healthy Japanese volunteers (control 1) were also obtained from the same region as the patients and were genotyped as controls. Only when a significant association $(\mathrm{p}<0.05)$ was obtained in control 1, was control $2(n=247)$ further tested. The 1997 American Thoracic Society (ATS) statement was followed to make a diagnosis of MAC pulmonary disease [3]. Briefly, all patients had clinical manifestations, small nodules with or without bronchiectasis on computed tomography images and positive smears or cultures of bacteria from at least three sputum samples, or histological or bacteriological evidence of the disease from bronchial or lung samples. Patients with obvious immunodeficiency, such as haematological malignancy, those who are under immunosuppressive therapy or those with HIV infection were excluded from this study. Comorbidity was described on the basis of a physician's diagnosis.

Differentiation of cultured mycobaterial species was routinely performed by PCR (AMPLICOR Mycobacterium tests; Roche Diagnostics, Basel, Switzerland). Clinical profiles and backgrounds of all subjects were extracted from medical records and interviews performed by trained medical staff.

\section{Genotyping of NRAMP1 polymorphisms}

Two polymorphisms of the NRAMP1 gene, 469+14 G/C in intron 4 (INT4; NCBI dbSNP ID rs3731865) and TGTG insertion and deletion polymorphism in the $3^{\prime}$ untranslated region (3'UTR; rs17235416), were analysed as described previously [21]. For genotyping of a nonsynonymous single nucleotide substitution at codon 543 in exon 15 (D543N; rs17235409), PCR was carried out with previously described primers [21], and the sequencing was performed using the Big Dye Terminator cycle sequencing method using ABI PRISM 3100 DNA Sequencer (Applied Biosystems, Foster City, CA, USA). For the genotyping of GT repeat polymorphisms of the promoter region of NRAMP1 [12], the PCR primer was designed as follows. The forward primer (5'-ACTCGCATTAGGCCAACGAG-3') was labelled with fluorescent dye. To avoid ambiguous typing, extra GT nucleotides were added to the $5^{\prime}$ end of the reverse primers $\left(5^{\prime}\right.$-(GT)TTCTGTGCCTCCCAAGTTAGC-3') [22]. PCR products were genotyped using ABI PRISM 377 DNA Sequencer (Applied Biosystems) according to the manufacturer's instructions. The fluorescent signals were analysed by GeneScan software and genotyped using Genotyper software (Applied Biosystems). Allele names of the GT repeat polymorphisms were designated as described by LIU et al. [21].

\section{Genotyping of VDR and MBL polymorphisms}

Two polymorphisms of the VDR gene, a C-to-T transition in exon 3 that creates an alternative initiation codon (rs10735810) and a T-to-C substitution in the 3'UTR of exon 10 (rs731236), were genotyped by digestion of PCR fragments with the Fok I and Taq I enzymes, respectively. PCR primers and enzymatic digestion have been described elsewhere [23].

Two polymorphisms of the $M B L$ gene, the $-221 \mathrm{X} / \mathrm{Y}$ (rs7096206) in the promoter and codon 54 A/B (rs1800450) in exon 1 , were genotyped by digestion of PCR fragments with the Btg I and Ban I enzymes, respectively. The PCR primer pair used was 5'-ACCTGGGTTTCCACTCATTCTCAT-3' and 5'CCCCAGGCAGTTTCCTCTGGAAGG-3'. Other known structural polymorphisms, C (codon 57; rs1800451) and D (codon 52; rs5030737), were not tested in the current study, as their frequencies have been reported to be extremely low in Asian populations [24]. All genotypes were determined by agarose gel electrophoresis of digested PCR fragments.

\section{Statistical analysis}

Disease association with each polymorphism was analysed by $2 \times n$ Fisher's exact test [25]. The current authors also examined whether genotype frequencies were in Hardy-Weinberg equilibrium in control subjects. Haplotype frequencies were estimated with an expectation-maximisation algorithm [25] and haplotype association tested using hapassoc [26]. A pvalue $<0.05$ was considered significant.

\section{RESULTS}

\section{Characteristics of patients with pulmonary MAC infection}

In total, 111 patients were involved in the current study (table 1). Following the study of PRINCE et al. [6], patients with pulmonary MAC infection were initially divided into two groups on the basis of the predisposing disease. The "MAC with comorbidity" group consisted of 53 patients with previous lung disease, including TB, chronic obstructive disease, pneumonia or other potential predisposing conditions, such as nonhaematological malignant disease, diabetes mellitus, or post-gastrectomy. The "MAC without comorbidity" group consisted of 58 patients who were otherwise normal and had no recognisable predisposing diseases such as those described previously. The average age at onset of disease was 61.9 versus 57.4 yrs in patients with and without comorbidity, respectively $(p=0.067)$. Females were more susceptible to MAC infection in the group without comorbidity $(86.2 \%)$ than with comorbidity $(67.9 \% ; \mathrm{p}=0.025)$. Approximately $90 \%$ of patients were infected with Mycobacterium avium and the remainder had $M$. intracellulare. The right middle lobe or lingular segment of the lung was mainly affected and this 


\begin{tabular}{|c|c|c|c|}
\hline \multirow[t]{2}{*}{ TABLE 1} & \multirow[t]{2}{*}{$\begin{array}{l}\text { istics of } p \\
\text { erium aviu }\end{array}$} & \multirow[b]{2}{*}{$\begin{array}{l}\text { MAC with } \\
\text { comorbidity }\end{array}$} & \multirow[b]{2}{*}{$\begin{array}{l}\text { MAC without } \\
\text { comorbidity }\end{array}$} \\
\hline & & & \\
\hline Cases & 111 & 53 & 58 \\
\hline Age at onset yrs & $59.5 \pm 12.5$ & $61.9 \pm 12.3$ & $57.4 \pm 12.3$ \\
\hline Male/female & $25 / 86$ & $17 / 36$ & $8 / 50$ \\
\hline Smoking history & 22 & 15 & 7 \\
\hline \multicolumn{4}{|l|}{ Mycobacterial species } \\
\hline M. avium & 91 & 43 & 48 \\
\hline M. intracellulare & 11 & 5 & 6 \\
\hline Unknown ${ }^{\#}$ & 9 & 5 & 4 \\
\hline \multicolumn{4}{|l|}{ Main lesion of disease } \\
\hline RML/lingular & 45 & 16 & 29 \\
\hline $\begin{array}{l}\text { RML/lingular and other } \\
\text { lobes }\end{array}$ & 38 & 22 & 16 \\
\hline Other lobes & 28 & 15 & 13 \\
\hline History of lung diseases & 40 & 40 & \\
\hline TB & 29 & 29 & \\
\hline COPD & 1 & 1 & \\
\hline Pneumonia & 11 & 11 & \\
\hline Lung cancer & 1 & 1 & \\
\hline Others & 5 & 5 & \\
\hline $\begin{array}{l}\text { History of other } \\
\text { predisposing diseases }\end{array}$ & 14 & 14 & \\
\hline Diabetes & 7 & 7 & \\
\hline Neoplasm & 5 & 5 & \\
\hline Gastrectomy & 2 & 2 & \\
\hline Others & 2 & 2 & \\
\hline
\end{tabular}

Data are presented as $\mathrm{n}$ or mean \pm SEM. M. avium: Mycobacterium avium M. intracellulare: Mycobacterium intracellulare; RML: right middle lobe; TB: tuberculosis; COPD: chronic obstructive pulmonary disease. ${ }^{\#}$ : MAC with no detailed information.

localisation of the legions was more frequently seen in the MAC patients without comorbidity than with comorbidity, although the statistical significance remained marginal $(p=0.052)$.

\section{Residence at onset of pulmonary MAC infection}

To examine whether the development of pulmonary MAC infection is related to an urban water supply, the locations at which the first signs and symptoms of MAC infection were noted, were plotted on a regional map of Tokyo, Japan (fig. 1) [27]. The residential information at the onset of the disease was available from 88 patients. The points where patients resided at the onset of the disease tended to be located in two areas, surrounding each hospital. As expected, there was a similar distribution of patients living in both areas. These areas were either supplied by the Tonegawa river water system or by a mixture of water systems from both the Tonegawa and Tamagawa rivers. The points of residence were not particularly concentrated on either the riverside or by the sea.

\section{Pulmonary MAC infection and NRAMP1 polymorphisms}

The results of case-control studies in patients with pulmonary MAC infection at four polymorphic loci of NRAMP1 are shown

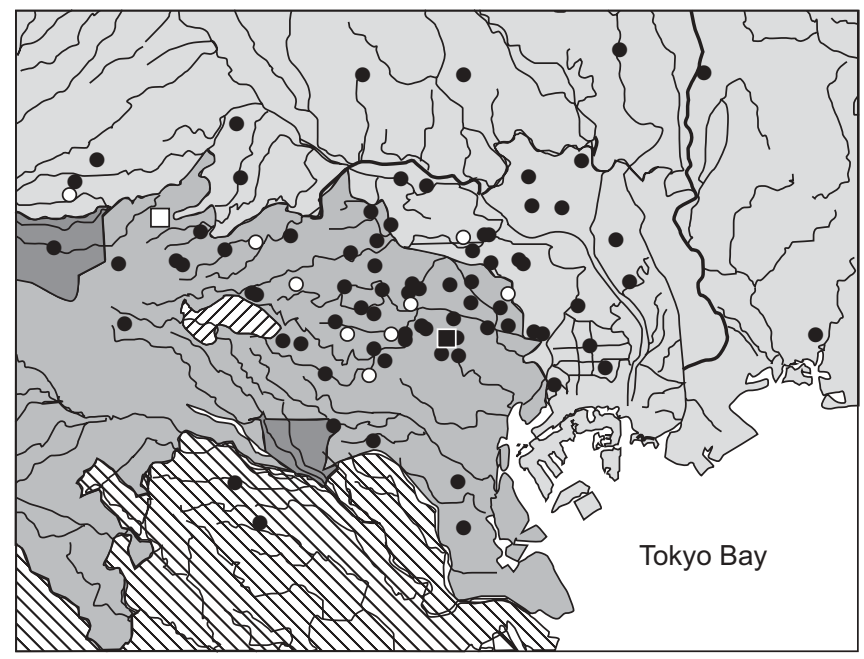

FIGURE 1. Residence at onset of pulmonary Mycobacterium avium complex (MAC) infection. The points where the first signs and symptoms of Mycobacterium avium (-) and $M$. intracellulare $(\bigcirc)$ infection were plotted on a regional map of Tokyo, with water systems in Tokyo superimposed. $\mathbf{a}$ : International Medical Center of Japan; $\square$ : National Hospital Organization Tokyo Hospital; $\square$ : Tonegawa river water system; $\mathbf{\square}$ : Tamagawa river water system; $\mathbf{\square}$ : combination of Tonegawa and Tamagawa water systems; $₫$ : Sagamigawa river water system; $\circlearrowright$ : other river water systems.

in table 2. The genotypic distribution of the D543N and TGTG insertion/deletion polymorphism was significantly different between MAC cases and controls $(p=0.026$ and $p=0.013$, respectively). Homozygotes for major alleles were more often observed in MAC cases than in controls. A similar association was observed in the analysis with the second set of controls as shown in table $2(p=0.003)$. A possible combined effect of the INT4 and 3'UTR polymorphisms, as reported previously [12], was also analysed. The overall comparison of combined genotypes did not show an association $(p=0.107$; data not shown). By haplotype analysis, there was no significant association between the INT4 and 3'UTR haplotypes and the pulmonary MAC infection ( $p=0.056$; data not shown). The presence of the haplotype carrying the INT4-C allele and 3'UTR-del allele was not estimated in the present subjects (data not shown).

\section{NRAMP1 D543N polymorphism and subgroups of pulmonary MAC infection}

Differences of genotypic distribution of D543N and TGTG insertion/deletion polymorphism between cases and controls led to the analysis of possible differences between subgroups of MAC cases and controls. The TGTG insertion/deletion polymorphism was in perfect linkage disequilibrium with D543N and the genotype distributions of D543N described in table 3 are also representative of the TGTG polymorphism. The D543N polymorphism showed significant associations with MAC infection without predisposing conditions or when the main lesion was limited to the right middle lobe or lingular segment of the lung $(\mathrm{p}=0.009$ and $\mathrm{p}=0.015$, respectively). Such associations were obtained when each group was compared with control 2 as well as control $1(p=0.006$ and $p=0.009$, respectively). In contrast, the subgroup with comorbidity or when the main lesion was neither in the right middle lobe nor 
TABLE 2 Relationship between the human natural resistance-associated macrophage protein 1 polymorphisms and pulmonary Mycobacterium avium complex (MAC) infection among the Japanese

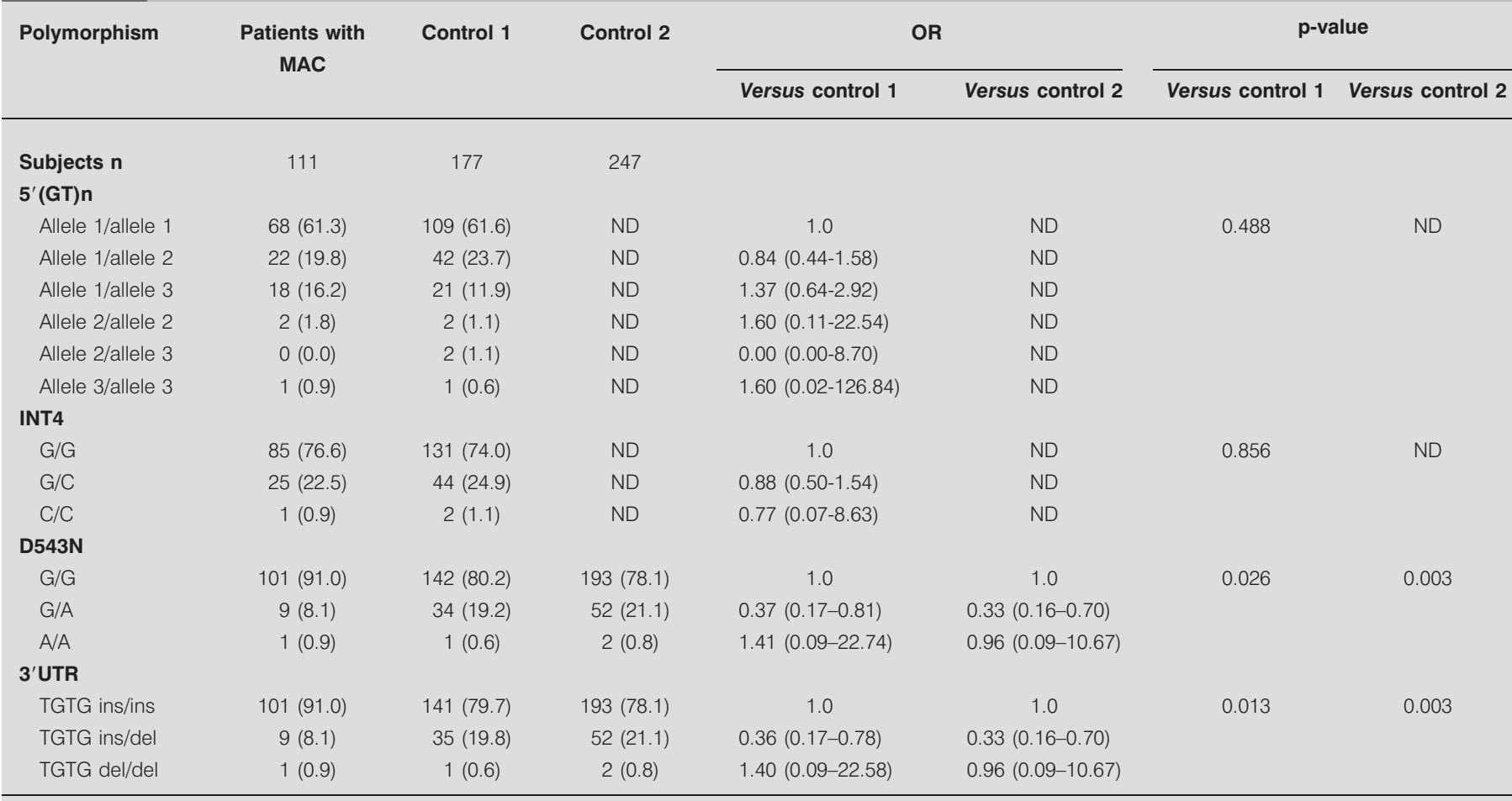

Data are presented as $\mathrm{n}(\%)$ or mean (95\% confidence interval), unless otherwise stated. Odds ratios (OR) represent the comparison between the most common homozygous genotype for each polymorphism. UTR: untranslated region; ins: insertion; del: deletion; ND: not done

the lingular segment, failed to show significant associations with this genotype, although the number of patients are comparable to the other subgroup. Genotypic distribution of these alleles shown in the control is similar to that reported in other Japanese studies [28, 29].

\section{Pulmonary MAC infection and VDR polymorphisms}

Two polymorphisms of the VDR gene, the Fok I polymorphism in exon 3 and Taq I polymorphism in exon 10, were also analysed. Distributions of both polymorphisms were not different between MAC cases and controls (table 4).

\section{Pulmonary MAC infection and MBL polymorphisms}

Two polymorphisms of the MBL gene, $-221 \mathrm{X} / \mathrm{Y}$ and codon 54 A/B polymorphisms were also tested. The distribution of both polymorphisms was not different between MAC cases and controls (table 5).

\section{DISCUSSION}

In general, interaction among pathogens, host factors and transmission routes are considered important for the development of infectious diseases. Although one report suggested that a familial aggregation of the disease is not caused by a

TABLE 3 Human natural resistance-associated macrophage protein 1 D543N polymorphism and subgroups of patients with pulmonary Mycobacterium avium complex infection

\begin{tabular}{|c|c|c|c|c|c|c|c|c|c|c|c|c|}
\hline \multirow[t]{2}{*}{ Genotype } & \multirow{2}{*}{$\begin{array}{c}\text { MAC } \\
\text { with } \\
\text { comorbidity }\end{array}$} & \multicolumn{2}{|c|}{ p-value } & \multirow{2}{*}{$\begin{array}{c}\text { MAC } \\
\text { without } \\
\text { comorbidity }\end{array}$} & \multicolumn{2}{|c|}{ p-value } & \multirow{2}{*}{$\begin{array}{c}\text { RML/ } \\
\text { lingular }\end{array}$} & \multicolumn{2}{|c|}{ p-value } & \multirow[t]{2}{*}{ Others } & \multicolumn{2}{|c|}{ p-value } \\
\hline & & $\begin{array}{l}\text { versus } \\
\text { control } 1\end{array}$ & $\begin{array}{c}\text { versus } \\
\text { control } 2\end{array}$ & & $\begin{array}{c}\text { versus } \\
\text { control } 1\end{array}$ & $\begin{array}{c}\text { versus } \\
\text { control } 2\end{array}$ & & $\begin{array}{l}\text { versus } \\
\text { control } 1\end{array}$ & $\begin{array}{c}\text { versus } \\
\text { control } 2\end{array}$ & & $\begin{array}{c}\text { versus } \\
\text { control } 1\end{array}$ & $\begin{array}{c}\text { versus } \\
\text { control } 2\end{array}$ \\
\hline $\begin{array}{l}\text { Subjects n } \\
\text { D543N }\end{array}$ & 53 & & & 58 & & & 45 & & & 66 & & \\
\hline $\mathrm{G} / \mathrm{G}$ & $47(88.7)$ & 0.399 & 0.213 & $54(93.1)$ & 0.009 & 0.006 & 42 (93.4) & 0.015 & 0.009 & 59 (89.4) & 0.212 & 0.114 \\
\hline$G / A$ & $6(11.3)$ & & & $3(5.2)$ & & & $2(4.4)$ & & & 7 (10.6) & & \\
\hline$A / A$ & $0(0.0)$ & & & $1(1.7)$ & & & $1(2.2)$ & & & $0(0.0)$ & & \\
\hline
\end{tabular}

Data are presented as $\mathrm{n}$ or $\mathrm{n}(\%)$, unless otherwise stated. RML: right middle lobe. 


\begin{tabular}{|c|c|c|c|c|}
\hline \multirow{2}{*}{$\begin{array}{l}\text { TABLE } 4 \\
\text { Polymorphism }\end{array}$} & \multicolumn{4}{|c|}{$\begin{array}{l}\text { Relationship between vitamin D receptor } \\
\text { polymorphisms and pulmonary Mycobacterium } \\
\text { avium complex (MAC) infection among the } \\
\text { Japanese }\end{array}$} \\
\hline & $\begin{array}{c}\text { Patients with } \\
\text { MAC }\end{array}$ & Controls & OR & $p$-value \\
\hline Subjects & 111 & 177 & & \\
\hline \multicolumn{5}{|l|}{ Fok I } \\
\hline$F / F$ & 43 (39.1) & $84(47.5)$ & 1.0 & 0.360 \\
\hline$F / f$ & $49(44.5)$ & 70 (39.5) & $1.37(0.82-2.30)$ & \\
\hline$f / f$ & $18(16.4)$ & $23(13.0)$ & $1.53(0.75-3.14)$ & \\
\hline \multicolumn{5}{|l|}{ Taq I } \\
\hline $\mathrm{T} / \mathrm{T}$ & 87 (79.1) & $132(74.6)$ & 1.0 & 0.635 \\
\hline$T / t$ & $22(20.0)$ & 41 (23.2) & $0.81(0.45-1.46)$ & \\
\hline$t / t$ & $1(0.9)$ & $4(2.2)$ & $0.38(0.04-3.45)$ & \\
\hline
\end{tabular}

Data are presented as $n, n$ (\%) or mean (95\% confidence interval). Odds ratios $(\mathrm{OR})$ represent comparisons between the most common homozygous genotype for each polymorphism.

single source of a particular virulent strain [10], molecular genetics of MAC causing pulmonary disease is rather limited.

When the mode of transmission of MAC is considered, a hospital water system or home water supply could represent a risk of MAC infection [2]. One study in South-East America [1] demonstrated that natural waters might be a source of pathogenic mycobacteria that can be transferred from water to air. The current authors plotted the place of residence of the subjects at the onset of the disease. Although this is not an allembracing cohort study, it may be possible to conclude that the distribution of subjects' residence is not concentrated in a specific city water system or waterfront.

Genetic predisposition would be involved in the development of pulmonary MAC infection for the following reasons. In the past, mutational defects of several genes were identified as a cause of congenital cellular immune deficiency in several families of a disseminated form of MAC infection [30]. Furthermore, two studies showed that the human leukocyte antigen (HLA) DR6 allele, encoded by the HLA-DRB1 gene, or an Asian HLA haplotype including DR6 is associated with sporadic cases of pulmonary MAC infection in the Japanese population [31, 32].

On the basis of strong influence of a mutation in the NRAMP1 gene on susceptibility to intracellular pathogens in mice, there has been considerable interest in the relevance of the human homologue, NRAMP1, in susceptibility to human mycobacterial infection [12-16]. With regard to the MAC infection, there are only a few reports with small sample sizes. HUANG et al. [17] analysed the $5^{\prime}(\mathrm{GT}) \mathrm{n}, \mathrm{D} 543 \mathrm{~N}$ and 3'UTR insertion/ deletion polymorphisms of the NRAMP1 gene in eight patients with MAC and were unable to find any particular characteristics of allele patterns. TANAKA et al. [10] analysed the coding region of the NRAMP1 gene in two Japanese families with pulmonary MAC infection, but were unsuccessful in finding any obvious abnormalities indicating immune deficiency.

\begin{tabular}{|c|c|c|c|c|}
\hline \multirow{2}{*}{$\begin{array}{l}\text { TABLE } 5 \\
\text { Polymorphism }\end{array}$} & \multicolumn{4}{|c|}{$\begin{array}{l}\text { Relationship between mannose binding lectin } \\
\text { polymorphisms and pulmonary Mycobacterium } \\
\text { avium complex (MAC) infection among the } \\
\text { Japanese }\end{array}$} \\
\hline & $\begin{array}{c}\text { Patients with } \\
\text { MAC }\end{array}$ & Controls & OR & $p$-value \\
\hline Subjects & 111 & 177 & & \\
\hline \multicolumn{5}{|l|}{-221} \\
\hline$x / X$ & $1(0.9)$ & $5(2.8)$ & $0.30(0.04-2.65)$ & 0.570 \\
\hline$X / Y$ & $20(18.0)$ & $35(19.8)$ & $0.87(0.47-1.60)$ & \\
\hline$Y / Y$ & $90(81.1)$ & $137(77.4)$ & 1.0 & \\
\hline \multicolumn{5}{|l|}{ Codon 54} \\
\hline $\mathrm{A} / \mathrm{A}$ & $73(65.8)$ & $115(65.0)$ & 1.0 & 0.790 \\
\hline$A / B$ & $34(30.6)$ & $52(29.4)$ & $1.03(0.61-1.74)$ & \\
\hline $\mathrm{B} / \mathrm{B}$ & $4(3.6)$ & $10(5.6)$ & $0.63(0.19-2.08)$ & \\
\hline
\end{tabular}

Data are presented as $\mathrm{n}, \mathrm{n}(\%)$ or mean (95\% confidence interval). Odds ratios (ORs) represent comparisons between the most common homozygous genotype for each polymorphism.

More recently, $\mathrm{KoH}$ et al. [18] reported a strong association between nontuberculous mycobacterial (NTM) lung disease including 18 patients with MAC infection and polymorphisms of the NRAMP1 gene in a Korean population. However, this data should be interpreted with care, as it is estimated that at least seven $(17.1 \%)$ of the 41 NTM patients possessed the 543-D and 3'UTR TGTG deletion haplotype, which had been thought to be rare in Asians [13, 16, 21, 33], including Korean TB patients [14]. Some factors unique to their study population, such as population stratification, might also have had an effect on the results, while the authors described uniformity of ethnicity.

To the current authors' knowledge, this is the first large-scale study in which $>100$ blood samples were collected for analysis of the candidate genes for pulmonary MAC infection. To exclude the possibility of false positives owing to a biased genotypic distribution of the controls, another set of controls were also tested and again significant association was observed. The allele frequency of the 543-N and TGTG deletion of $3^{\prime}$ UTR were significantly lower in the MAC group than in controls. Although the amino acid change in the coding region and 3'UTR polymorphism of the NRAMP1 gene might influence the function and mRNA levels of the gene, respectively, the functional significance of these polymorphisms has not yet been investigated extensively. It is not surprising that the (GT)n promoter polymorphism of the NRAMP1 gene was not associated with MAC infection in the present study, as earlier studies analysing genomic structure around the NRAMP1 gene demonstrated that linkage disequilibrium is not strong enough between the $5^{\prime}$ and $3^{\prime}$ end of the gene $[12,21,33]$, namely the (GT)n repeats and D543N/ TGTG polymorphisms, although the D543N and TGTG insertion/deletion polymorphism are in perfect linkage disequilibrium. It is interesting that in a West African population, the same 3'UTR deletion allele was similarly low in subjects with a paucibacillary tuberculoid form of leprosy, where a 
T-helper cell (Th)1-type response is more predominant, than in multibacillary form, which is associated with a Th2-type immune response [15]. Conversely, however, the study by BELLAMY et al. [12] clearly showed that all four polymorphisms were associated with smear-positive TB and the 543-N and TGTG deletion showed a more positive association with TB in Gambians, whereas, in a Cambodian population, the 543-N and TGTG deletion showed a negative association with active TB [16]. Apparently divergent findings may be explained by the presence of another possible susceptibility variant [33]. In the study by BELLAMY et al. [12], a strong association was demonstrated by combined analysis of the INT4 and 3'UTR variants. However, in the current study, the GC/+del allele did not increase the risk for development of pulmonary MAC disease. The haplotype carrying the INT4-C allele and 3'UTRdel allele, which were both reported as susceptible alleles in the study of BeLLAMY et al. [12], might not exist in the Japanese population according to the current frequency estimation. This might partly explain the differences between the present study and the report from an African population [12].

The present authors classified patients into two groups, with or without predisposing risk factors, as described in the 1997 ATS statement [3]. Most MAC patients without a predisposing condition were elderly females, and the right middle lobe or lingular segment of the lung was mainly affected. This appears to be one of the characteristics of pulmonary MAC infection without comorbidity [6-8]. Although the mechanism is unknown, changes in hormonal balance accompanied with ageing might be involved in the development of the disease [34]. The NRAMP1 polymorphism showed a relatively strong association with MAC infection where there is no predisposing condition or in cases where the main lesion is limited to the right middle lobe or lingular segment of the lung. In contrast, the subgroup without this phenotype did not show significant associations. It is consistent with the notion that a certain genetic predisposition underlies this particular phenotype in affected individuals. When the results of previous and future studies on MAC infection are assessed, this phenotypic effect should be taken into account.

\section{CONCLUSION}

The current authors investigated the human natural resistanceassociated macrophage protein 1 , vitamin $\mathrm{D}$ receptor and mannose binding lectin gene polymorphisms, previously reported as candidate genes determining susceptibility to mycobacterial infection, and demonstrated a possible influence of the natural resistance-associated macrophage protein 1 polymorphisms on the development of pulmonary $\mathrm{Myco-}$ bacterium avium complex infection. Possible genetic risk factors that permit infection with Mycobacterium avium complex in otherwise normal individuals could be targeted for future therapeutic intervention.

\section{ACKNOWLEDGEMENTS}

The authors wish to thank: A. Mikami, S. Izumi, M. Kamimura, H. Kawada and A. Yoshizawa (International Medical Center of Japan, Tokyo, Japan), and Y. Kawabe, K. Masuda, M. Nishiyama and Y. Tanaka (National Hospital Organization Tokyo Hospital, Tokyo, Japan) for making the patients under their care available; M. Okochi (International Medical Center of
Japan) for her technical assistance; and K. Tanabe (International Medical Center of Japan) for critical reading the manuscript. The authors would especially like to thank S. Akagawa and N. Nagayama (National Hospital Organization Tokyo Hospital) for their continuous encouragement.

\section{REFERENCES}

1 Wendt SL, George KL, Parker BC, Gruft H, Falkinham JO 3rd. Epidemiology of infection by nontuberculous Mycobacteria. III. Isolation of potentially pathogenic mycobacteria from aerosols. Am Rev Respir Dis 1980; 122: 259-263.

$2 \mathrm{du}$ Moulin GC, Stottmeier KD, Pelletier PA, Tsang AY, Hedley-Whyte J. Concentration of Mycobacterium avium by hospital hot water systems. JAMA 1988; 260: 1599-1601.

3 Diagnosis and treatment of disease caused by nontuberculous mycobacteria. Medical Section of the American Lung Association. Am J Respir Crit Care Med 1997; 156: S1-S25.

4 Sakatani M. Nontuberculous mycobacteriosis; the present status of epidemiology and clinical studies. Kekkaku 1999; 74: 377-384.

5 Henry MT, Inamdar L, O'Riordain D, Schweiger M, Watson JP. Nontuberculous mycobacteria in non-HIV patients: epidemiology, treatment and response. Eur Respir J 2004; 23: 741-746.

6 Prince DS, Peterson DD, Steiner RM, et al. Infection with Mycobacterium avium complex in patients without predisposing conditions. $N$ Engl J Med 1989; 321: 863-868.

7 Reich JM, Johnson RE. Mycobacterium avium complex pulmonary disease. Incidence, presentation and response to therapy in a community setting. Am Rev Respir Dis 1991; 143: 1381-1385.

8 Reich JM, Johnson RE. Mycobacterium avium complex pulmonary disease presenting as an isolated lingular or middle lobe pattern. The Lady Windermere syndrome. Chest 1992; 101: 1605-1609.

9 Tanaka E, Amitani R, Niimi A, Suzuki K, Murayama T, Kuze F. Yield of computed tomography and bronchoscopy for the diagnosis of Mycobacterium avium complex pulmonary disease. Am J Respir Crit Care Med 1997; 155: 20412046.

10 Tanaka E, Kimoto T, Matsumoto $\mathrm{H}$, et al. Familial pulmonary Mycobacterium avium complex disease. Am J Respir Crit Care Med 2000; 161: 1643-1647.

11 Vidal SM, Malo D, Vogan K, Skamene E, Gros P. Natural resistance to infection with intracellular parasites: isolation of a candidate for Bcg. Cell 1993; 73: 469-485.

12 Bellamy R, Ruwende C, Corrah T, McAdam KP, Whittle HC, Hill AV. Variations in the NRAMP1 gene and susceptibility to tuberculosis in West Africans. $N$ Engl J Med 1998; 338: 640-644.

13 Gao PS, Fujishima S, Mao XQ, et al. Genetic variants of NRAMP1 and active tuberculosis in Japanese populations. International Tuberculosis Genetics Team. Clin Genet 2000; 58: 74-76.

14 Ryu S, Park YK, Bai GH, Kim SJ, Park SN, Kang S. 3'UTR polymorphisms in the NRAMP1 gene are associated with susceptibility to tuberculosis in Koreans. Int J Tuberc Lung Dis 2000; 4: 577-580. 
15 Meisner SJ, Mucklow S, Warner G, Sow SO, Lienhardt C, Hill AV. Association of NRAMP1 polymorphism with leprosy type but not susceptibility to leprosy per se in west Africans. Am J Trop Med Hyg 2001; 65: 733-735.

16 Delgado JC, Baena A, Thim S, Goldfeld AE. Ethnic-specific genetic associations with pulmonary tuberculosis. J Infect Dis 2002; 186: 1463-1468.

17 Huang JH, Oefner PJ, Adi V, et al. Analyses of the NRAMP1 and IFN-gammaR1 genes in women with Mycobacterium avium-intracellulare pulmonary disease. Am J Respir Crit Care Med 1998; 157: 377-381.

18 Koh WJ, Kwon OJ, Kim EJ, Lee KS, Ki CS, Kim JW. NRAMP1 gene polymorphism and susceptibility to nontuberculous mycobacterial lung diseases. Chest 2005; 128 : 94-101.

19 Bellamy R, Ruwende C, Corrah T, et al. Tuberculosis and chronic hepatitis $\mathrm{B}$ virus infection in Africans and variation in the vitamin D receptor gene. J Infect Dis 1999; 179: 721-724.

20 Soborg C, Madsen HO, Andersen AB, Lillebaek T, Kok-Jensen A, Garred P. Mannose-binding lectin polymorphisms in clinical tuberculosis. J Infect Dis 2003; 188: 777-782.

21 Liu J, Fujiwara TM, Buu NT, et al. Identification of polymorphisms and sequence variants in the human homologue of the mouse natural resistance-associated macrophage protein gene. Am J Hum Genet 1995; 56: 845-853.

22 Brownstein MJ, Carpten JD, Smith JR. Modulation of nontemplated nucleotide addition by Taq DNA polymerase: primer modifications that facilitate genotyping. Biotechniques 1996; 20: 1004-1006.

23 Curran JE, Vaughan T, Lea RA, Weinstein SR, Morrison NA, Griffiths LR. Association of A vitamin D receptor polymorphism with sporadic breast cancer development. Int J Cancer 1999; 83: 723-726.

24 Lipscombe RJ, Beatty DW, Ganczakowski M, et al. Mutations in the human mannose-binding protein gene: frequencies in several population groups. Eur J Hum Genet 1996; 4: 13-19.

25 The $\mathrm{R}$ project for statistical computing. http://www.rproject.org. Date last updated: March 2003. Date last accessed: February 24, 2006.

26 Burkett K, McNeney B, Graham J. A note on inference of trait associations with SNP haplotypes and other attributes in generalized linear models. Hum Hered 2004; 57: 200-206.

27 The Bureau of Waterworks, Tokyo Metropolitan Government. Water Resources and Supply Areas. http:// www.waterworks.metro.tokyo.jp. Date last accessed: August 28, 2005.

28 Ouchi K, Suzuki Y, Shirakawa T, Kishi F. Polymorphism of SLC11A1 (formerly NRAMP1) gene confers susceptibility to Kawasaki disease. J Infect Dis 2003; 187: 326-329.

29 Abe T, Iinuma Y, Ando M, et al. NRAMP1 polymorphisms, susceptibility and clinical features of tuberculosis. I Infect 2003; 46: 215-220.

30 Ottenhoff TH, Verreck FA, Lichtenauer-Kaligis EG, Hoeve MA, Sanal O, van Dissel JT. Genetics, cytokines and human infectious disease: lessons from weakly pathogenic mycobacteria and salmonellae. Nat Genet 2002; 32: 97-105.

31 Kubo K, Yamazaki Y, Hanaoka M, et al. Analysis of HLA antigens in Mycobacterium avium-intracellulare pulmonary infection. Am J Respir Crit Care Med 2000; 161: 1368-1371.

32 Takahashi M, Ishizaka A, Nakamura H, et al. Specific HLA in pulmonary MAC infection in a Japanese population. Am J Respir Crit Care Med 2000; 162: 316-318.

33 Yip SP, Leung KH, Lin CK. Extent and distribution of linkage disequilibrium around the SLC11A1 locus. Genes Immun 2003; 4: 212-221.

34 Tsuyuguchi K, Suzuki K, Matsumoto H, Tanaka E, Amitani R, Kuze F. Effect of oestrogen on Mycobacterium avium complex pulmonary infection in mice. Clin Exp Immunol 2001; 123: 428-434. 